\title{
Editorial
}

\section{Large Infection Problems in Small Patients Merit a Renewed Emphasis on Prevention}

\author{
Nalini Singh, MD, MPH
}

One who maintains one's hygiene through cleanliness derives ten bodily benefits, whereas, one who is moderate in one's diet gets only six benefits.-Vidur (from the Vedas, 1500 $\mathrm{BC})$

Advances in neonatal care have improved the survival of immature, very low birth weight (VLBW) infants. These infants $(<1,500 \mathrm{~g})$ experience a disproportionate share of healthcare-associated infections (approximately $75 \%$ ) compared with other newborns in the neonatal intensive care unit (NICU), ${ }^{1,2}$ The number of sepsis episodes increases with decreasing birth weight. Complications related to prematurity and late-onset sepsis are associated with increased morbidity and mortality and higher healthcare costs. These infants have a significantly longer hospital stay (79 vs 60 days; $P<.001)$ and higher mortality rate (18\% vs $7 \% ; P<.001) .^{3}$ This issue of Infection Control and Hospital Epidemiology contains multiple important articles focusing on infections, their consequences, and/or their prevention among NICU patients. ${ }^{4-8}$

In high-risk infants, there may be an increase in the incidence of healthcare-associated infections due to multidrug-resistant gram-negative organisms. ${ }^{9,10}$ In a multicenter study from the Neonatal Research Network of the National Institute of Child Health and Human Development, among 5,447 patients, the increased use of intrapartum antimicrobials for the prevention of group B streptococcal disease was associated with a decrease in the incidence of early-onset ( $<3$ days) group B streptococcal sepsis (from 5.9 to 1.7 per 1,000 live births) but an increase in sepsis with ampicillin-resistant Escherichia coli isolates (from 3.2 to 6.8 per 1,000 live births). ${ }^{11}$ The mortality rate also is higher for VLBW infants with infections due to gram-negative organisms (36\%; odds ratio for gram-negative vs other organisms, $3.5 ; P<001) .{ }^{3}$ Three of the articles in this issue of Infection Control and Hospital Epidemiology deal with outbreaks of Serratia marcescens infections among NICU patients. ${ }^{4-6}$

High-risk infants acquire gram-negative infections either endogenously or exogenously. The major endogenous reservoir for many organisms, such as Enterobacteriaceae and Candida, is the large intestine of the patient. ${ }^{12}$ Exogenously, $S$. marcescens has been acquired through the contaminated hands of healthcare workers or through contaminated soap, equipment, or milk. ${ }^{1318} S$. marcescens, a member of the Enterobacteriaceae family, is responsible for outbreaks in NICUs that are difficult to control due to persistent gastrointestinal colonization. ${ }^{19-22}$ In a point-prevalence survey of 29 NICUs in the United States, it caused only $5 \%$ of healthcare-associated infections. ${ }^{1}$ The clinical spectrum of disease varies from colonization, ophthalmic infections such as conjunctivitis, and endophthalmitis to invasive infections such as bacteremia, meningitis, and cerebral abscess. ${ }^{2334}$

Intestinal colonization along with selective pressure exerted by the widespread use of antimicrobial agents plays an important role in healthcare-associated infections and colonization among VLBW infants..$^{10,12,35}$ These infants are prime targets for the spread of pathogens of healthcareassociated infections because of lack of bowel control, close proximity of patients, and frequent patient movements within the NICU to accommodate staffing needs. Any breach in infection control practices can lead to horizontal spread via the hands of healthcare workers, or through the use of shared, contaminated equipment. 
Studies in this issue of Infection Control and Hospital Epidemiology by Milisavljevic et al., ${ }^{4}$ Sarvikivi et al., ${ }^{5}$ and Lai et al. ${ }^{6}$ illustrate (1) the ability of $S$. marcescens to cause sporadic outbreaks in populations of vulnerable infants hospitalized in NICUs over months to years; (2) protean clinical manifestations ranging from simple colonization to conjunctivitis and sepsis; (3) resistance to various antimicrobial agents, thereby limiting the therapeutic options of clinicians; (4) use of molecular epidemiologic tools such as pulsed-field gel electrophoresis to confirm clonal outbreaks of S. marcescens; (5) the need for aggressive infection control measures to limit spread of the organisms (performing active surveillance cultures, cohorting infected or colonized patients, assessing staffing, performing environmental cultures, enforcing hand hygiene, and installing alcohol-based hand gels in locations convenient to the staff); and (6) similar risk factors for these infections such as low gestational age, low birth weight, and frequency of invasive procedures.

In addition to the control measures outlined above, Lai et al. ${ }^{6}$ also banned artificial fingernails among their staff. Whether artificial fingernails are responsible for the transmission of pathogens of healthcare-associated infections is unknown. ${ }^{36}$ However, healthcare workers who wear them are more likely to harbor gram-negative pathogens before and after washing their hands, and they have been implicated in other outbreaks involving Pseudomonas aeruginosa. ${ }^{37-40}$ Healthcare workers should be discouraged from wearing long or artificial fingernails when caring for high-risk patients.

Overcrowding and understaffing are common themes in these outbreaks of $S$. marcescens and in previously published studies. ${ }^{41,42}$ Currently, healthcare is an "industry" with a corporate culture and hospitals continue to admit patients to remain financially solvent despite staffing problems. Front-line healthcare workers are facing, on a daily basis, the challenges of managing increasingly complex patients, who require intensive support. Meticulous hand hygiene is one of the many tasks they need to perform while caring for multiple patients. Noncompliance with this practice has the potential to spread the pathogens of healthcare-associated infections from person to person.

Enhanced infection control measures are needed when epidemiologically significant organisms are detected by either active surveillance or clinical cultures. $S$. marcescens is an organism of epidemiologic significance due to its ability to not only cause invasive infection in neonates and outbreaks, but also acquire resistance to antimicrobial agents frequently used in NICUs. ${ }^{10,43-45}$ Various DNA-based molecular typing methods are available and should be integrated into the investigation of an outbreak. Many have been used in "real time" to allow NICUs to remain open while genetically distinct strains are being identified. ${ }^{46-51}$

Another important article in this issue of Infection Control and Hospital Epidemiology found that administration of inadequate empiric antimicrobial therapy was associated with worse outcomes among NICU patients with bloodstream infection, as previously demonstrated in multiple studies of adult patients. ${ }^{7}$ In a cohort of 229 patients, 45 neonates had 90 episodes of bloodstream infection. Only $14 \%$ of these episodes occurred in the first 7 days of life and $86 \%$ occurred after this period. Isolation of coagulase-negative staphylococci in blood cultures may reflect either a true infection or a contaminant. A limitation noted by the authors of this study was that a single positive blood culture from an indwelling catheter was considered to represent a bloodstream infection even when a coagulase-negative staphylococci was grown. Neonates with Candida species sepsis were more likely to die as a result of not receiving appropriate antimicrobial treatment within 48 hours of performing a blood culture. Empiric antifungal therapy for at-risk VLBW neonates was proposed previously based on a clinical predictive model that had a sensitivity of $85 \%$ and a specificity of $47 \% 52$; empiric antifungal treatment was recommended if neonates had a gestational age below 25 weeks, thrombocytopenia, or a history of thirdgeneration cephalosporin or carbapenem therapy in the 7 days before obtaining blood for culture.

Although routine infection control practices may seem too simple to address the complexity of the issue at hand, their faithful application has been shown to be effective. In this issue of Infection Control and Hospital Epidemiology, Won et al. found that a multifaceted motivational approach for improving compliance with hand hygiene using both positive and negative reinforcement strategies was associated with a significant reduction in healthcare-associated infections among NICU patients, especially respiratory tract infections. ${ }^{8}$ The healthcare community is encouraged to once again return to basics while using molecular typing as needed to confirm apparent outbreaks. It is important to remember that infection control is everyone's responsibility.

\section{REFERENCES}

1. Sohn AH, Garrett DO, Sinkowitz-Cochran RL, et al. Prevalence of nosocomial infections in neonatal intensive care unit patients: results from the first national point-prevalence survey. J Pediatr 2001;139:821-827.

2. National Nosocomial Infections Surveillance (NNIS) System. National Nosocomial Infections Surveillance (NNIS) System report: data summary from January 1992 to June 2002, issued August 2002. Am J Infect Control 2002;30:458-475.

3. Stoll BJ, Hansen N, Fanaroff AA, et al. Late-onset sepsis in very low birth weight neonates: the experience of the NICHD Neonatal Research Network. Pediatrics 2002;110:285-291.

4. Milisavljevic V, Wu F, Larson E, et al. Molecular epidemiology of Serratia marcescens outbreaks in two neonatal intensive care units. Infect Control Hosp Epidemiol 2004;25:719-721.

5. Sarvikivi E, Lyytikäinen O, Salmenlinna S, et al. Clustering of Serratia marcescens infections in a neonatal intensive care unit. Infect Control Hosp Epidemiol 2004;25:723-729.

6. Lai KK, Baker SP, Fontecchio SA. Rapid eradication of a cluster of Serratia marcescens in a neonatal intensive care unit: use of epidemiologic chromosome profiling by pulsed-field gel electrophoresis. Infect Control Hosp Epidemiol 2004;25:730-734.

7. Apisarnthanarak A, Holzmann-Pazgal G, Hamvas A, Olsen MA, Fraser VJ. Antimicrobial use and the influence of inadequate empiric antimicrobial therapy on the outcomes of nosocomial bloodstream infections in a neonatal intensive care unit. Infect Control Hosp Epidemiol 2004;25:735-741.

8. Won S-P, Chou H-C, Hsieh W-S, et al. Handwashing program for the prevention of nosocomial infections in a neonatal intensive care unit. Infect Control Hosp Epidemiol 2004;25:742-746.

9. Nambiar S, Singh N. Change in epidemiology of health care-associated 
infections in a neonatal intensive care unit. Pediatr Infect Dis $J 2002$ 21:839-842.

10. Singh N, Patel KL, Leger M-M, et al. Risk of resistant infections with enterobacteriaceae in hospitalized neonates. Pediatr Infect Dis $J 2002$ 21:1029-1033.

11. Stoll BJ, Hansen N, Fanaroff AA. Changes in pathogens causing earlyonset sepsis in very-low-birth weight infants. $N$ Engl J Med 2002;347:240 247.

12. Donskey $\mathrm{CJ}$. The role of the intestinal tract as a reservoir and source for transmission of nosocomial pathogens. Clin Infect Dis 2004;39:219-226.

13. Archibald LK, Corl A, Shah B, et al. Serratia marcescens outbreak associated with extrinsic contamination of $1 \%$ chlorxylenol soap. Infect Control Hosp Epidemiol 1997;18:704-709.

14. Fleisch F, Zimmermann-Baer U, Zbinden R, et al. Three consecutive outbreaks of Serratia marcescens in a neonatal intensive care unit. Clin Infect Dis 2002;34:767-773.

15. Gransden WR, Webster M, French GL, Phillips I. An outbreak of Serratia marcescens transmitted by contaminated breast pumps in a special care baby unit. J Hosp Infect 1986;7:149-154.

16. Jones BL, Gorman IJ, Simpson J, et al. An outbreak of Serratia marcescens in two neonatal intensive care units. I Hosp Infect 2000; 46:314-319.

17. Manning ML, Archibald LK, Bell LM, Banerjee SN, Jarvis WR. Serratia marcescens transmission in a pediatric intensive care unit: a multifactorial occurrence. Am J Infect Control 2001;29:115-119.

18. Moloney AC, Quoraishi AH, Parry P, Hall V. A bacteriological examination of breast pumps. / Hosp Infect 1987;9:169-174.

19. Christensen GD, Korones SB, Reed L, Bulley R, McLaughlin B, Bisno AL. Epidemic Serratia marcescens in a neonatal intensive care unit: importance of the gastrointestinal tract as a reservoir. Infect Control 1982;3:127-133.

20. Montanaro D, Grasso GM, Annino I, De Ruggiero N, Scarcella A, Schioppa F Epidemiological and bacteriological investigation of Serratia marcescens epidemic in a nursery and in a neonatal intensive care unit. $J$ Hyg (Lond) 1984;93:67-78.

21. Belokrysenko SS, Shestopalov NV, Geras'kina VP, Parfeniuk RF. Microbial ecology and a retrospective assessment of the possibility of predicting an outbreak of suppurative meningitis caused by a Serratia marcescens strain in a hospital for the nursing care of premature infants [in Russian]. Zh Mikrobiol Epidemiol Immunobiol 1992;2:28-31.

22. Newport MT, John JF, Michel YM, Levkoff AH. Endemic Serratia marcescens infection in a neonatal intensive care nursery associated with gastrointestinal colonization. Pediatr Infect Dis $J$ 1985;4:160-167.

23. Raskind CH, Sabo BE, Callan DA, Farrel PA, Dembry LM, Gallagher PG. Conjunctival colonization of infants hospitalized in a neonatal intensive care unit: a longitudinal analysis. Infect Control Hosp Epidemiol 2004;25:216-220.

24. Bhujwala RA, Shriniwas, Kalra V, Bose M. Serratia marcescens septicaemia in a newborn. Indian J Med Res 1977;65:623-627.

25. Campbell JR, Diacovo T, Baker CJ. Serratia marcescens meningitis in neonates. Pediatr Infect Dis J 1992;11:881-886.

26. Sakata H, Maruyama S. Serratia marcescens brain abscess in a newborn [in Japanese]. Kansenshogaku Zasshi 1998;72:845-848.

27. Collins SM, Correa H, Ortenberg J. Prostatic abscess in the newborn: an unrecognized source of urosepsis. Urology 2001;57:554

28. de Courten C, Sancho P, BenEzra D. Metastatic Serratia marcescens endophthalmitis. J Pediatr Ophthalmol Strabismus 1988;25:45-47.

29. Grauel EL, Halle E, Bollmann R, Buchholz P, Buttenberg S. Neonatal septicaemia: incidence, etiology and outcome. A 6-year analysis. Acta Paediatr Scand Suppl 1989;360:113-119.

30. Harris GJ, DiClementi D. Congenital dacryocystocele. Arch Ophthalmol 1982;100:1763-1765.

31. Khan EA, Wafelman LS, Garcia-Prats JA, Taber LH. Serratia marcescens pneumonia, empyema and pneumatocele in a preterm neonate. Pediatr Infect Dis J 1997;16:1003-1005.

32. Messerschmidt A, Prayer D, Olischar M, Pollak A, Birnbacher R. Brain abscesses after Serratia marcescens infection on a neonatal intensive care unit: differences on serial imaging. Neuroradiology 2004;46:148-152. 33. Muhlbauer B, Fattal A, Siegman-Igra Y. A small outbreak of Serratia marcescens sepsis and meningitis. Isr J Med Sci 1983;19:980-981.

34. Nakamura Y, Nohara M, Nakashima T, et al. Meningoencephalitis due to Serratia marcescens infection in neonates. Hum Pathol 1984;15:651656.

35. Wake C, Lees $\mathrm{H}$, Cull AB. The emergence of Serratia marcescens as a pathogen in a newborn unit. Aust Paediatr I 1986;22:323-326.

36. Boyce JM, Pittet D. Guideline for hand hygiene in health-care-settings: recommendations of the Healthcare Infection Control Practices Advisory Committee and the HICPAC/SHEA/IDSA Hand Hygiene Task Force. $M M W R$ 2002;51(RR16):1-44

37. Passaro DJ, Waring L, Armstrong R, et al. Postoperative Serratia marcescens wound infections traced to an out-of-hospital source. J Infect Dis 1997;175:992-995.

38. Finland M. Excursions into epidemiology: selected studies during the past four decades at Boston City Hospital. J Infect Dis 1973;128:76-124.

39. Moolenaar RL, Crutcher M, San Joaquin VH, et al. A prolonged outbreak of Pseudomonas aeruginosa in a neonate intensive care unit: did staff's fingernails play a role in disease transmission? Infect Control Hosp Epidemiol 2000;21:80-85.

40. McNeil SA, Foster CL, Hedderwick SA, Kauffman CA. Effect of hand cleansing with antimicrobial soap or alcohol-based gel on microbial colonization of artificial fingernails worn by health care workers. Clin Infect Dis 2001;32:367-372.

41. Smith PJ, Brookfield DS, Shaw DA, Gray J. An outbreak of Serratia marcescens infections in a neonatal unit. Lancet 1984;1:151-153.

42. van Ogtrop ML, van Zoeren-Grobben D, Verbakel-Salomons EM, van Boven CP. Serratia marcescens infections in neonatal departments: description of an outbreak and review of the literature. I Hosp Infect 1997;36:95-103.

43. Bompard Y, Lambert T, Gantzer A, Chastel A, Voinnesson A, Aufrant C. Use of imipenem-cilastatin in neonatal septicemias caused by gram-negative bacilli multiresistant to beta-lactam antibiotics [in French]. Pathol Biol (Paris) 1988;36:521-524.

44. Bujdakova H, Hanzen J, Jankovicova S, et al. Occurrence and transferability of beta-lactam resistance in Enterobacteriaceae isolated in Children's University Hospital in Bratislava. Folia Microbiol (Praha) 2001;46:339-344.

45. Lewis DA, Hawkey PM, Watts JA, et al. Infection with netilmicin resistant Serratia marcescens in a special care baby unit. $\mathrm{Br}$ Med J (Clin Res Ed) 1983;287:1701-1705.

46. Hoyen C, Rice $\mathrm{L}$, Conte S, Jacobs MR, Walsh-Sukys M, Toltzis P. Use of real time pulsed field gel electrophoresis to guide interventions during a nursery outbreak of Serratia marcescens infection. Pediatr Infect Dis $J$ 1999;18:357-360.

47. Singh N, Leger M, Campos C. Use of REP-PCR in confirming spread of vancomycin resistant Enterococcus faecium among hospitalized neonates. Presented at the Interscience Conference on Antimicrobial Agents and Chemotherapy; September 27-30, 2002; San Diego, CA. Abstract 453.

48. Olive DMB. Principles and applications of methods for DNA-based typing of microbial organisms. J Clin Microbiol 1999;37:1661-1669.

49. McGeer A, Low DE, Penner J, Ng J, Goldman C, Simor AE. Use of molecular typing to study the epidemiology of Serratia marcescens. J Clin Microbiol 1990;28:55-58.

50. Steppberger K, Walter S, Claros MC, et al. Nosocomial neonatal outbreak of Serratia marcescens: analysis of pathogens by pulsed field gel electrophoresis and polymerase chain reaction. Infection 2002;30:277281.

51. Waters V, Larson E, Wu F, et al. Molecular epidemiology of gram-negative bacilli from infected neonates and health care workers' hands in neonatal intensive care units. Clin Infect Dis 2004;38:1682-1687.

52. Benjamin DKJr, DeLong ER, Steinbach WJ, Cotton CM, Walsh TJ, Clark $\mathrm{RH}$. Empirical therapy for neonatal candidemia in very low birth weight infants. Pediatrics 2003;112:543-547. 
NOW AVAILABLE

from Infectio Diagnostic (IDI)

IDI-MRSA ${ }^{\mathrm{Tm}}$

\section{Helps Minimize Transmission of Nosocomial Infection}

Next in IDI's series of fast and accurate DNA-based diagnostic tests, IDI-MRSA ${ }^{\text {TM }}$ :

- detects methicillin resistance in Staphylococcus aureus

- eliminates false positives from coagulase-negative staphylococci

\section{One test provides all the answers}

- Speed: results in 1 hour

- Simplicity: direct from a nasal swab

- Sensitivity: $93 \%$

- Specificity: $96 \%$

Using real-time PCR Smart Cycler ${ }^{*}$ automated analysis, IDI's breakthrough assay eliminates the need for labor-intensive, time-consuming culture detection, offering an extremely effective way to reduce:

- MRSA-related morbidity and mortality

- the financial burden associated with managing MRSA infections$$
\text { IDI-MRSA }
$$

Revolutionizing Screening Practices

For more information, or to obtain a complimentary IDI-MRSA ${ }^{\mathbf{T M}}$ information insert, please contact our local distributor:

Cepheid (USA): 1-888-336-2743

Somagen (Canada): 1-800-661-9993

\section{(III)}




\section{THE PRICE OF OUR}

\section{HEPA FILTRATION}

\section{WON'T LEAVE YOU}

\section{COUGHING}

And you will breathe easier knowing you're also getting the smallest, quietest, most effective HEPA filtration machine in its class!

Small: Weighing in at 53 pounds and dimensions of 40"X12"X18" the Recirculator II is the smallest, most portable unit available.

Quiet: At $53 \mathrm{dbA}$ the Recirculator II is an average of $6 \mathrm{dbA}$ lower than other competing brands.

Effective: With 535 cubic feet per minute and dual HEPA filtration, the Recirculator II is the only choice for your tuberculosis control needs.

\section{$\$ 1,895.00$}
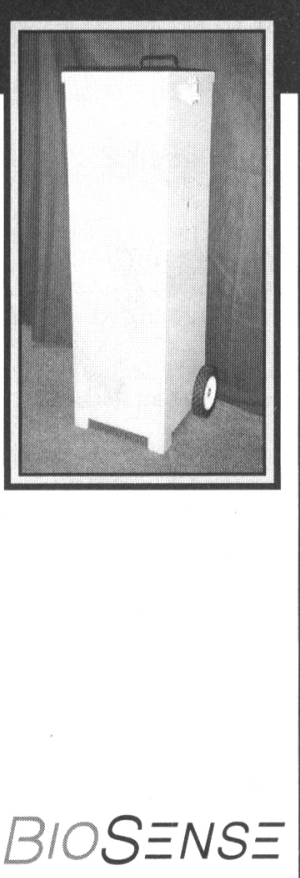

Phone (800) 941-2844 Fax (408) 270-4457
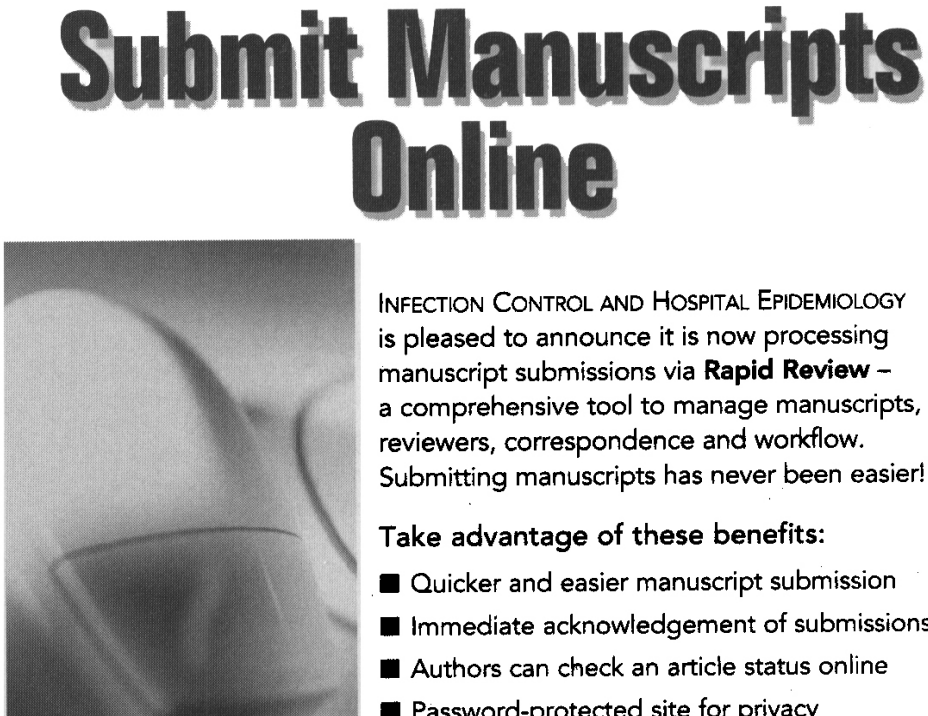

INFECTION CONTROL AND HOSPITAL EPIDEMIOLOGY is pleased to announce it is now processing manuscript submissions via Rapid Review a comprehensive tool to manage manuscripts, reviewers, correspondence and workflow. Submitting manuscripts has never been easier!

Take advantage of these benefits:

- Quicker and easier manuscript submission

Immediate acknowledgement of submissions

- Authors can check an article status online

Password-protected site for privacy

To submit your manuscripts online, visit RapidReview.com

\section{EpiQuest ${ }^{\circledR}$}

\section{“Making Time for Prevention"}

THE Healthcare Epidemiology Software!

EpiQuest $(\mathbb{R})$ is powerful software for automated data collection and reporting that enables interventional epidemiology. Quickly identify, analyze, and monitor historic and current trends of any risk, event, threat, drug, procedure, or disease and especially Healthcare Acquired Infections.

EpiQuest ${ }^{\circledR}$ is for Safe Environment Challenges of effective Surveillance, Prevention, \& Control. Save time with EpiQuest ${ }^{\circledR}$ Data Imports from Patient demographics, Encounters (Admissions), Laboratory, Pharmacy and Operating Room data systems. Data Mine, Export, Report and Graph findings. Benchmark internally \& externally with the latest CDC NNIS data.

Easily track Antibiotic Resistant organism frequencies and locations in Alert Organism. Analyze Antibiotic pressures to Resistant Organism infections, community and healthcare acquired. EpiQuest ${ }^{\circledR}$ readily supports Outbreak Management and Syndromic Surveillance for Bioterrorism threats. EpiQuest $(\mathbb{R})$ is equally effective across all care levels and in any PC/Tablet/ LAN/WAN/Wireless or Cable environment. Meet JCAHO 2004-5 Standards with EpiQuest ${ }^{\circledR}$.

Use the new EpiQuest ${ }^{\circledR}$ Statistics Program companion with standard Incidence Density (device days), Chi-Square or Fisher's Exact analysis tools. NNIS surveillance data tables for SSI, BSI and VAP rates are included. Create P-, NP-, C- and U-Process Control reports and charts. 